\title{
Um ensaio inédito de Guimarães Rosa
}

Frederico Antonio Camillo Camargo ${ }^{1}$

O estilo deve ser os muitos homens no

homem, através das muitas coisas

que o homem supõe ver.

Guimarães Rosa, "Liquidificador"

Guimarães Rosa não exerceu a crítica ou teorizou sobre o fazer literário de modo oficial e premeditado. Sua colaboração em periódicos restringe-se quase inteiramente a textos ficcionais e poéticos. A obra publicada em livros compõe-se de um romance, cinco livros de narrativas curtas ${ }^{2}$, um de poesia e um último em que se mesclam poemas, pequenos contos, crônicas, depoimentos e composições que podem ser, sem muito rigor, chamadas de poemas em prosa. Nesse conjunto de textos, vamos encontrar apenas alguns poucos cuja forma se aproxima do ensaio: os prefácios de Tutameia.

Em caráter não oficial, entretanto, é possível, pontualmente, surpreender juízos críticos de Rosa, por exemplo, nas entrevistas que concedeu. Lembramos, todavia, que o número delas é reduzido: a sua aversão por prestar depoimentos a jornalistas tornou-se célebre e caricatural. As entrevistas efetivamente realizadas, por sua vez, apresentam observações vagas e superficiais (também devido a uma limitação do próprio gênero), e, até mesmo, recusas, sobretudo quando o tema são seus parceiros de profissão literária. Walnice Nogueira Galvão confirma essa postura rosiana:

Quando ia avançada sua carreira, já alçado ao posto de escritor mais admirado do país e com seus livros traduzidos para as principais línguas de cultura, Guimarães Rosa se fecharia em copas e evitaria enfarruscar os ânimos, sonegando palpites estéticos sobre quais parâmetros que deveriam vigorar na literatura brasileira.

I Mestrando pelo Departamento de Teoria Literária e Literatura Comparada da Faculdade de Filosofia, Letras e Ciências Humanas da Universidade de São Paulo (USP, São Paulo, SP, Brasil). E-mail: frederico.camargo@usp.br

2 Dentro da classificação "narrativas curtas", estou incluindo os contos de Sagarana, Primeiras estórias, Tutameia e Estas estórias, e as novelas de Corpo de baile. 
Essa prudência nunca desmentida nota-se não só nos escritos, mas, sobretudo, nas escassas e reticentes entrevistas. ${ }^{3}$

Na mais famosa delas, realizada por Günter Lorenz, em 1965, Rosa chega a afirmar:

Não me agrada julgar meus colegas. Sim, portanto, não insista; é melhor falarmos de Dostoievski, Goethe, Tolstoi ou de Schweijik, de Flaubert e Balzac, mas não de meus compatriotas escritores. Um autor jamais deveria falar de outros autores, mesmo que não os aprecie. Disto não resulta nada de razoável; penetra-se em mundos estranhos, e isto não conduz a nada. ${ }^{4}$

O segundo grande repositório potencial de opiniões de Guimarães Rosa sobre Literatura é a sua correspondência. Dela, desde a década de 1970, vêm sendo publicadas cartas trocadas com interlocutores específicos, por iniciativa deles próprios ou de pesquisadores. Uma carta importante desse conjunto, e que, até hoje, recebeu pouca atenção da crítica, é a enviada ao tio Vicente Guimarães, em que Rosa, ainda no início da carreira literária, revela, com certo detalhe, seus pressupostos como escritor ${ }^{5}$. De forma mais consistente, porém, são as cartas com os tradutores Edoardo Bizarri e Curt Meyer-Clason, que contêm maior número de elementos da visão rosiana de Literatura (a sua própria, é verdade, bem mais do que a literatura feita por outros escritores) ${ }^{6}$.

O acervo pessoal de Guimarães Rosa (formado de arquivo e biblioteca), adquirido em 1973 pelo Instituto de Estudos Brasileiros da Universidade de São Paulo (IEB-USP), além de abrigar ainda grande parte da correspondência inédita do autor, armazena outros numerosos elementos para a investigação de suas preferências e opiniões literárias. A biblioteca, composta de mais de três mil volumes, guarda suas

3 GALVÃO, W. N. Sobre o regionalismo. In: - Mínima mímica: ensaios sobre Guimarães Rosa. São Paulo: Companhia das Letras, 2008. p. 113.

4. LORENZ, G. Diálogo com Guimarães Rosa. In: Diálogo com a América Latina: panorama de uma literatura do futuro. São Paulo: E.P.U., p. 315-355, 1973, p. 331.

5 GUIMARÃES, V. Joãozito: a infância de Guimarães Rosa. São Paulo: Panda Books, 2006. p. 132. Essa carta é comentada por Walnice Nogueira Galvão, no ensaio já citado.

6 Vale lembrar que parte considerável da correspondência de Guimarães Rosa ainda está inédita: em especial a trocada com a tradutora para o inglês, Harriet de Onís, o tradutor para o francês, Jean-Jacques Villard, e o tradutor para o espanhol, Angel Crespo, sem falar na vasta correspondência pessoal. 
anotações à margem de muitos livros7; no arquivo, uma série documental intitulada Estudos para obra (da qual fazem parte cadernetas de viagem, cadernos de estudos e diários, além de vasto material de pesquisa do escritor) está povoada de citações de autores de interesse, bem como comentários esparsos sobre arte e literatura ${ }^{8}$. Por fim, entre os manuscritos de narrativas, poemas e discursos de Guimarães Rosa, sobressaem-se alguns textos, fragmentários e inacabados, que podem ser considerados ensaios.

\section{Guimarães Rosa ensaísta}

Tomando como referência seus livros mais populares, a imagem que temos de Guimarães Rosa é a de um grande narrador de histórias. Como poeta, o legado de Rosa é equívoco: os poemas de Ave, palavra (antes, também publicados em periódicos) foram escritos sob o abrigo de heterônimos anagramáticos, e Magma não tinha, até a data da morte do autor, previsão de ser publicado. Já os outros textos nãonarrativos em prosa - os prefácios-ensaios de Tutameia e algumas composições de Ave, palavra - não alcançam acolhida, a não ser por parte de estudiosos.

A produção não-ficcional de Rosa, porém, não se esgota nessas últimas referências. Se o discurso de posse na Academia Brasileira de Letras conquistou certa celebridade, tendo, muitas vezes, (os mesmos) trechos profusamente reproduzidos por críticos e curiosos, o autor compôs, proferiu e publicou ainda, pelo menos, uma meia-dúzia de outros discursos, desde a formatura na Faculdade de Medicina, passando pela recepção do prêmio Machado de Assis. Também pouco conhecidos e comentados são: o depoimento escrito em homenagem ao seu editor alemão, Joseph Witsch, intitulado "O Reno e o Urucuia"9; o comentário ao livro $O$ ciclo do carro de boi no Brasil, de Bernardino José de

7 Parte dessas anotações já foi analisada em SPERBER, S. F. Caos e Cosmos - Leituras de Guimarães Rosa. São Paulo: Duas Cidades, 1976.

8 O mapeamento e a análise dessa série são os objetivos de minha dissertação de mestrado pelo Departamento de Teoria Literária e Literatura Comparada da FFLCH-USP, sob a orientação da Profa. Dra. Sandra Guardini Teixeira Vasconcelos, cujo título provisório é Os estudos para obra de João Guimarães Rosa.

9 A história da composição desse texto e a sua transcrição integral podem ser lidas na correspondência entre Guimarães Rosa e Curt Meyer-Clason. Alguns comentários sobre o depoimento estão em SOETHE, P. A. A imagem da Alemanha em Guimarães Rosa como retrato auto-irônico. Revista Scripta, Belo Horizonte, v.9, n. 17, p. 287-zol, 2. sem. 2005 . 
Souza, publicado no Boletim Bibliográfico Brasileiro, em 1958; a crônica "Os doces", publicada no jornal A Manhã, em 1953; o "Parecer sobre a unificação da ortografia portuguesa”, de $1967^{10}$; um editorial publicado no jornal Correio da Manhã, em 1951, chamado "Balanceamento de poderes"; e, igualmente, alguns prefácios e orelhas de livros, escritos, fatalmente, a partir de pedidos dos próprios autores. (Alguns dos agraciados foram: Paulo Rónai, Vasconcellos Costa, Geraldo França de Lima, Eduardo Barreiros Canabrava e Gilberto Freyre ${ }^{11}$.)

A verve ensaística de Guimarães Rosa, ainda que relativamente pobre em exemplares, sistematização e popularidade, não é incompreensível. Tendo o autor acumulado, durante sua vida, extraordinária quantidade de informações através de viagens, leituras e pesquisas, seria natural que esse conhecimento procurasse encontrar uma vazão outra que não fossem as narrativas de ficção. Indício do desejo rosiano de dar forma a esse tipo de discurso é uma nota fragmentária e sem datação, encontrada entre os papéis de pesquisa que constituem o universo dos Estudos para Obra de seu arquivo. Diz a anotação:

\section{Ms\% - Ensaios: \\ Saudade \\ Prostituição \\ Literatura erótica ${ }^{12}$}

O símbolo m\% (aqui, acrescido de "s" para indicar o plural), conhecido dos estudiosos dos manuscritos de Guimarães Rosa, caracteriza o texto que o segue como uma criação ou apropriação do autor. Sem outros dados contextuais (essa nota não apresenta relação com as que a antecedem ou sucedem), a listagem acima, composta de apenas três itens, parece agrupar temas sobre os quais Rosa teria a intenção de escrever ensaios. Infelizmente, entretanto, não existem, no arquivo do escritor, planos ou esboços desses possíveis textos.

Outras composições de natureza ensaística, todavia, todas incompletas e apresentando grau variado de desenvolvimento, como já mencionado anteriormente, estão presentes entre os manuscritos

10 Guimarães Rosa fez parte de uma comissão que analisou a proposta de unificação da ortografia portuguesa.

11 As referências bibliográficas completas desses textos podem ser encontradas no volume dos Cadernos de Literatura Brasileira, do Instituto Moreira Salles, dedicado a João Guimarães Rosa.

12 Fundo João Guimarães Rosa, Instituto de Estudos Brasileiros. Código do documento: JGR-EO-18,o3, p. 56A. 
e materiais de pesquisa de Guimarães Rosa. Sob o título "Crueldade Culinária”, por exemplo, Rosa tece, em cinco folhas manuscritas, considerações sobre o uso de carne de animais na alimentação humana; o texto “O jaboti e a tartaruga", numa versão manuscrita e outra datiloscrita, discorre sobre questões de originalidade em literatura e as coincidências do uso de certas figuras e expressões por autores diferentes; ou, então, concluindo extenso material de pesquisa sobre línguas eslavas, o ensaio "Russismos" discute a influência do idioma russo no português. Finalmente, o mais extenso e, talvez, mais destacado desses projetos de ensaios, com o curioso título de "Liquidificador", torna-se, a partir de agora, nosso objeto de descrição e comentário.

\section{Liquidificador}

O ensaio compõe-se de 35 folhas datilografadas em folhas de dimensão aproximada de $20 \mathrm{~cm} \times 25 \mathrm{~cm}$, com a palavra CÓPIA impressa em vermelho no verso, e coladas sobre folhas de dimensão aproximada de $21 \mathrm{~cm} \times 31 \mathrm{~cm}$, com o timbre do Ministério das Relações Exteriores, escondido pela folha superior. Sobre o registro datilográfico foram feitas intervenções a lápis - rasuras, acréscimos, correções -, o que sugere um trabalho de revisão do texto por parte de Rosa. É possível que a numeração das folhas, também a lápis, tenha sido realizada pela equipe que organizou e acondicionou o material, havendo um lapso na contagem e registro: o mesmo número 34 aparece nas duas últimas folhas. Os títulos também foram acrescentados após a datilografia: no extremo da margem superior, lê-se a palavra "LEITURAS", e, imediatamente abaixo, "NOTAS PARA UM TESTAMENTO". Ambas as inscrições foram riscadas a lápis, mas permanecem legíveis. Por fim, destituído de rasura, em nova linha, aparece o título "LIQUIDIFICADOR”. Não há datação explícita no manuscrito, nem balizas temporais precisas. A única data de referência é o ano de 1950, em que o autor revela ter lido uma série de artigos de jornal publicados na revista Paris Match. Não há assinatura, nem sinal de finalização do texto.

Estruturalmente, o ensaio está organizado em 4/4 seções. Rosa esboça a ideia de atribuir números a essas seções, mas a numeração é abandonada em 5. As seções são separadas por um, ou mais de um, sinal “+”. A característica principal do ensaio, portanto, antecipada pelos títulos e sustentada pela divisão em seções, é a ausência de uma unidade temática ou de um grande fio condutor que informe o discurso. O título "Leituras" reflete parcialmente o conteúdo do ensaio, pois, em muitas 
das seções, Guimarães Rosa comenta leituras que fez; "Notas para um testamento" também oferece pistas para a motivação e conformação do texto: a sua pulverização em seções dá a ele, de fato, a aparência de um conjunto de notas independentes, enquanto a palavra "testamento" nos permite interpretá-lo como uma espécie de balanço: um momento em que Rosa quer reunir, antes do final de sua vida, opiniões e reflexões que não conseguiu escrever e publicar ${ }^{13}$; o terceiro título, "Liquidificador", acentua a ideia de um espaço em que elementos diferentes podem ser colocados e misturados para formar uma só matéria; a epígrafe do ensaio, a mesma epígrafe que o autor utilizará, futuramente, na seção IV de "Sobre a escova e a dúvida", prefácio de Tutameia, conta o episódio do louco que vai a Paris e causa uma série de confusões ${ }^{14}$.

Do que foi dito anteriormente, depreende-se que o estilo do ensaio é livre, e, às vezes, bastante informal. Ao longo das seções, temas e ideias se sucedem sem rigor. Esse tipo de configuração pode até colocar em perigo o status do texto como ensaio. Não será antes um depoimento, ou um registro íntimo de impressões? Pelo menos duas características do texto obrigam rejeitar a hipótese de um registro pessoal e privado. Primeiro, o fato de ter sido feita uma revisão da primeira versão datilografada. Segundo - apesar de isso não ser inédito, mesmo em diários -, a própria forma de composição do discurso supõe a existência de um leitor: em várias passagens, por exemplo, Rosa pede desculpas, caso sua opinião ofenda alguém. Finalmente, uma característica extrínseca ao texto fornece um argumento ainda mais determinante: o manuscrito estava acondicionado originalmente em uma pasta de cartolina em que Rosa anotou, à mão: "Pequenos ensaios".

De maneira bastante esquemática e resumida, as seções do ensaio e os respectivos temas abordados são os seguintes:

- Seção 1: A importância dos clássicos e a falta de publicidade para eles;

- Seções 2 e 3: Comentário sobre Dostoiévski e seu substrato filosófico;

13 Não podemos deixar de considerar certo aspecto irônico na expressão "notas para um testamento", lembrando a liberdade do morto de falar do que desejar, sem preocupações com a repercussão no mundo dos vivos. Essa lição já foi dada por Brás Cubas.

14. É de se esperar que Rosa não tivesse a ideia de utilizar a mesma epígrafe para dois textos diferentes, o que nos faz acreditar que o ensaio inacabado é anterior à primeira publicação de "Sobre a escova e a dúvida", em 1965. Igualmente, a seção 15 repete o argumento sobre o absurdo do uso da escova de dentes imediatamente após o acordar. 
- Seções 4 e 5: Comentários sobre traduções de $A$ divina comédia;

- Seções 6 e 7: Elogio a Augusto dos Anjos;

- Seção 8: Elogios aos livros Amor imortal e O louco do Cati;

- Seção 9: Comentário sobre expressões do Corão;

- Seção 10: Comentário sobre uma aparição inesperada da poesia no cotidiano;

- Seção 11: Compêndio de poesia grega: os poetas Píndaro e Anacreonte;

- Seções 12 e 13: Transcrição de passagens do Diário de bordo de Cristóvão Colombo; comentário sobre Colombo e a chegada à América;

- Seções 14 a 16: Elogio a Edmundo da Luz Pinto; comentário sobre a expressão "aplicação de métodos ordinários aos acontecimentos extraordinários" e seu possível complemento: "aplicação de métodos extraordinários aos acontecimentos ordinários";

- Seções 17 e 18: Jesus Cristo como psicólogo; o domínio dos próprios sentimentos;

- Seções 19 e 20: "visão extraordinária dos acontecimentos ordinários": elogio aos ingleses;

- Seção 21: Frase de Oscar Wilde;

- Seção 22: Tradução de um epitáfio rural da Suábia;

- Seção 23: Transcrição de versos de Camões;

- Seção 24: Transcrição de frases sobre a inveja;

- Seção 25: Transcrição de trecho de um relatório do Ministério das Relações Exteriores: episódio com um índio;

- Seção 26: Discussão da noção de "gênio";

- Seções 27 e 28: Comentário sobre influências em literatura;

- Seção 29: Comentário sobre Napoleão;

- Seção 30: Transcrição de poema de Camões, em que Rosa coloca as letras de todas as palavras de forma invertida e substitui algumas ("c" por "k", por exemplo), para dar a impressão de uma língua desconhecida;

- Seção 31: Transcrição de soneto de Camões (“Alegres campos, verdes arvoredos");

- Seção 32: Comentário sobre o estilo;

- Seção 33: Comentário sobre expressão linguística "Meça-se e despeça-se";

- Seção 34: Elogio da oração;

- Seção 35: Comentários sobre as traduções do "Pai-Nosso"; 
- Seção 36: Ainda comentário sobre a atividade da oração;

- Seção 37 a 39: A poesia no cotidiano: comentário sobre o "Oscar" e topônimos curiosos, em diversos países.

- Seção 40: Transcrição e tradução de versos de Safo;

- Seção 41: Transcrição e tradução de uma canção de ninar grega;

- Seção 42: Transcrição de um trecho de soneto de juventude; discussão sobre o material de que eram feitos os sapatos da Cinderela;

- Seção 43: Transcrição de trecho de Os Maias, sobre o pé de uma personagem;

- Seção 44: Transcrição de um conto de Eça de Queirós: "O gato Bonifácio".

Discutir extensiva e minuciosamente o ensaio de Guimarães Rosa é impossível no escopo deste artigo. Nosso objetivo, aqui, será comentar algumas seções cujos temas revelem opiniões do autor sobre o fazer literário e suas preferências estéticas.

\section{A difusão da obra literária: problemas de tradução}

É comum que ensaios críticos de escritores reflitam preocupações sobre a sua própria literatura, mesmo quando falem de literatura, de modo geral e abstrato, ou de outros autores, de forma particular. Esse ensaio de Guimarães Rosa não é exceção a esse preceito. Já na sua abertura vem posta uma reflexão sobre a recepção e a permanência da obra literária, questão que sempre esteve no horizonte do autor.

Os grandes livros - e tenham os bois logo nomes: a Bíblia, a Ilíada, a Odisséia, a Divina Comédia, todo Shakespeare, todo o Goethe, todo Platão principalmente, todo Camões, e fico nos que frequento mais - são a leitura mais atual, mais moderna e mais quotidianamente aproveitável que possa haver. Infelizmente, sua publicidade é mal feita. [p. 1] $]^{15}$

15 Todos os excertos do ensaio têm a seguinte referência: Fundo João Guimarães Rosa, Instituto de Estudos Brasileiros. Código do documento: JGR-M-21,ol. Indicarei, portanto, ao lado dos trechos transcritos, apenas os números das páginas. 
Também a questão da originalidade está em jogo: somente conhecendo a (melhor) tradição literária, o escritor é capaz de criar uma obra que não a repita, mas que a complemente:

Mas felizmente para muitos, escritores, que, se os conhecessem [os grandes livros], deixavam de escrever tanta coisa em que os repetem relesmente, reproduzindo-os de décima ou vigésima mão. [p. 1]

A difusão e o conhecimento das grandes obras, no entanto, passam pelo delicado e turbulento processo de tradução. Para ilustrar os problemas que podem advir de um trabalho de tradução mal realizado, Rosa toma como exemplo duas traduções de $A$ divina comédia: uma realizada por Artaud de Montor e outra efetuada por um tradutor de quem Rosa desconhece o nome. Sobre o primeiro, Rosa atira:

Mas, o que na verdade páginas a fora se perpetra, é a mais grosseira, a mais monstruosa, a mais infame das traições. Onde havia poesia, o Cavaleiro Artaud de Montor deu volta. Crasso, impermeável. Foi dentro de um escafandro que ele atravessou aquele mar. [p. 2]

A respeito do segundo, a avaliação é menos rude, mas a conclusão é a mesma:

A tradução é honesta, feita por um poeta inteligente e com sensibilidade, e que se informa bem, estudou Dante, conhece o terreno onde pisa. Tudo isto se vê, da amostra. Mas vê-se também, mais uma vez, como é quase impossível verter-se poesia, língua a língua, conservada a forma externa: rima e metro. Temos a sombra de uma árvore. Brasa apagada. Perdeu-se quase tudo: força, concisão, pique, originalidade, atmosfera, música subjacente, magia - a poesia. O fluido não passa, quase nunca. No final, fica o vulgar. [p. 5, grifos do autor]

A obra de Guimarães Rosa começou a ser publicada no estrangeiro em 1958 ("A hora e a vez de Augusto Matraga”, tradução para o francês). Nessa mesma época, o autor inicia correspondência com três dos seus primeiros tradutores: Harriet de Onís (inglês), Curt MeyerClason (alemão) e Edoardo Bizzarri (italiano). Já foi apontada, em outros estudos, a dedicação de Rosa no auxílio aos seus tradutores, revelando seus pressupostos estéticos, respondendo a dúvidas linguísticas, montando glossários de flora e fauna, e mesmo revisando partes 
das traduções e apresentando sugestões. Como enunciado no início de "Liquidificador", tal como ocorre com os "grandes livros", Guimarães Rosa sabe que sua obra só permanecerá se for competentemente difundida ao redor do mundo. Se a tradução delas não for adequada, a sua posição no cânone estará ameaçada.

Sobre a tradução inglesa de Grande sertão: veredas, por exemplo, em carta a Curt Meyer-Clason, de 17 de junho de 1963, Rosa faz críticas muito semelhantes às que transcrevemos a respeito das traduções de A divina comédia. Um trecho específico dessa carta combina, no entanto, o desgosto com a tradução com o desejo de publicidade:

O livro americano está cheio dessas falhas, e ainda mais fundas alterações, enfraquecimentos, omissões, cortes. Basta compará-lo com o original, em qualquer página. Com tudo isso, porém, reconheço que os tradutores merecem meu aplauso e gratidão, pelos enormes esforços com que operaram, dando ao mundo o GRANDE SERTÃO em inglês, abrindo para ele um grande caminho, se Deus quiser. ${ }^{16}$

A tradução, como vemos, é, ao mesmo tempo, um problema e uma solução. Podemos perceber, também, que o primeiro tema de "Liquidificador", mesmo disfarçado de uma discussão sobre os grandes livros e as traduções de $A$ divina comédia, é motivado por uma inquietação pessoal de Guimarães Rosa. Essa será a tônica do ensaio. Já dizia Montaigne nos seus Ensaios: "sou eu mesmo a matéria de meu livro"17.

\section{Originalidade e influências em literatura}

Não ocupa menor importância, entre os interesses de Guimarães Rosa relativos à recepção e avaliação de sua obra, o famigerado tema das influências entre autores. O arquivo do escritor testemunha seu ávido esforço de colecionar as críticas a seus livros, formando um acervo de mais de 2 mil artigos. Essa fortuna crítica, como é de se esperar, está

16 ROSA,J.G. João Guimarães Rosa: Correspondênciacom seutradutoralemão CurtMeyerClason:(1958-1967). Rio de Janeiro: Nova Fronteira/Academia Brasileira de Letras; Belo Horizonte: Editora da UFMG, 2003. p. 115-116. Cheguei a essa carta a partir da leitura de VASCONCELOS, S. G. T. João \& Harriet (notas sobre um diálogo intercultural). In FANTINI, M. Machado e Rosa: leituras críticas. Cotia: Ateliê Editorial, 2oı, p. 153-161.

17 MONTAIGNE, M. Os ensaios. Livro I. São Paulo: Martins Fontes, 2ooo, p. 4. 
repleta de especulações e comparações de Rosa com outros escritores, ocorrência que nem sempre satisfaz um criador que se quer original. Em "Liquidificador", de qualquer forma, não é sobre si mesmo que Rosa faz considerações explícitas: "Normalmente, todo escritor devia de ser original - já que cada criatura humana é, no fundo, tão diferente das outras, quase uma espécie por si” (p. 19), diz ele. O autor, entretanto, admite a impossibilidade de se esquivar das influências, mas exige que sejam levados em consideração todos os tipos de influência, e não somente aquelas de natureza literária:

as influências - inevitáveis - tinham de ser gerais: de todos os escritores lidos, das coisas vistas, dos filmes, dos jornais, das conversas, do que se come, do que se bebe, do zumbido dos mosquitos e da dor-de-cabeça, de tudo - tudo, enfim. [p. 19]

Em socorro de seu argumento, Rosa cita como exemplos Perto do coração selvagem, de Clarice Lispector, e $O$ amanuense Belmiro, de Cyro dos Anjos. O primeiro, qualificado de joyceano pela crítica, é assim avaliado por Rosa: "mais aproximado seria dizerem da Autora que era uma nietzscheana que tivesse lido 'Katherine Mansfield', seu 'Diário' inclusive" (p. 19). Do segundo, rotulado por muitos de machadiano, Rosa diz não ter precisado "seguir mestre nenhum" (p. 19).

Desde a publicação de Sagarana, em 1946, grande parte da crítica, como é de praxe, procurou entender e justificar o "fenômeno" Guimarães Rosa a partir da sua vinculação com uma tradição literária preexistente que lhe teria servido de modelo: mais marcadamente, o regionalismo. André Luís de Campos, em dissertação de mestrado sobre a recepção crítica de Sagarana, realiza um levantamento quase completo dos nomes aos quais Rosa foi associado:

A crítica, para compreender Rosa, realiza a fusão de horizontes, isto é, compara-o a Gustavo Corção, Lúcio Cardoso, Afonso Arinos, Fialho de Almeida, Monteiro Lobato, Coelho Neto, Graciliano Ramos, Raquel de Queirós, José Lins do Rego, José Mauro de Vasconcelos, Jorge Amado, Mário de Andrade, Valdomiro Silveira, Rudyard Kipling e Miguel Torga. ${ }^{18}$

18 CAMPOS, A. L. de. A travessia crítica de Sagarana, 275 p. 2002. Dissertação de Mestrado em Teoria Literária, Instituto de Estudos da Linguagem, Universidade Estadual de Campinas, Campinas, 2002. p. 45. 
O crítico Oswaldino Marques, já em 1956, mas tomando como base somente Sagarana, “Com o vaqueiro Mariano", "Pé-duro, Chapéu de couro" e "Aquário", ao comentar a "profusão desnorteante do seu vocabulário", coloca Rosa lado a lado com Simões Lopes Neto, Euclides da Cunha, Aquilino Ribeiro, Kipling, Joyce, Melville e Gallegos ${ }^{19}$. O nome de Joyce será cada vez mais citado a partir das publicações de Corpo de baile e Grande sertão: veredas.

Em pelo menos uma oportunidade, Rosa rejeita algumas dessas aproximações. Em carta a Mary Lou Daniel, de 3 de novembro de 1964, cujos trechos foram publicados no livro João Guimarães Rosa: travessia literária, o autor explica:

De Joyce, só li parte do Dubliners. O Ulysses, fiz várias tentativas, que nunca foram além de pedaços de páginas. Acho nele um ludismo, uma atitude que não me é simpática, excessiva intencionalidade formal, muitíssimo de "voulu", que me repele... Mário de Andrade, polêmico, ligado a um Movimento, partiu de um desejo de 'abrasileirar' a todo custo a língua, de acordo com postulados que sempre achei mutiladores, plebeizantes e empobrecedores da língua, além de querer enfeá-la, denotando irremediável maugosto. Faltava-lhe, a meu ver, finura, sensibilidade estética... (Em todo caso, adorei ler o Macunaíma, que, na ocasião, me entusiasmou Será que há influências sutis, que a gente mesmo é incapaz de descobrir de si?) $)^{20}$

Escritor de sucesso, Rosa não alimenta simpatia pelos críticos, como revela, em 1965, na entrevista a Gunter Lorenz: “(...) não tenho uma opinião muito favorável sobre a crítica (...). No começo da minha carreira vários deles me atacaram sem absolutamente me compreenderem (...) quase sempre a crítica não tem valor nem interesse, é apenas perda de tempo" "21. A defesa de Clarice Lispector e Cyro dos Anjos contra influências que julga disparatadas não deixa de ser também uma defesa de si próprio. Mas o programa de Rosa não é somente acusar a "pressa" do crítico, que "atribui influências que nunca existiram” (p 19). Também o autor de literatura pode ter culpa dessas associações indevidas:

19 MARQUES, O. Ensaios escolhidos. Rio de Janeiro: Civilização Brasileira, 1968, p. 85.

20 DANIEL, M. L. João Guimarães Rosa: travessia literária. Rio de Janeiro: Livraria José Olympio Editora, 1968, p. 73.

21 LORENZ, G. op. cit., p. $33^{2}$. 
A meu ver, talvez seja que esses influenciados procuram de propósito a influência - consciente ou inconscientemente - por timidez, por medo, apenas: não ousam sair à rua sem um apadrinhamento indireto. [p. 19, grifos do autor]

A questão subjacente a esses comentários de Guimarães Rosa é o problema da originalidade. Por originalidade, entenda-se, particularmente, a recusa da imitação das fórmulas herdadas, seja no trato com a língua, seja na aplicação de procedimentos narrativos. Na carta enviada a seu tio, Vicente Guimarães, ainda em 1947, Rosa é enfático na rejeição de um certo tipo de literatura que se fazia à época: "[você está] intoxicado suave e imperceptivelmente, pela má literatura simplista e calhorda, que reinou e abundou entre nós (...). Agora, porém, a hora é de combate, de ofensiva". ${ }^{22}$ Assim, ao finalizar suas notas sobre Clarice ("Mas, na verdade, trata-se de obra pessoal e independente, sozinha e bela em sua autônoma poesia", p. 19) e Cyro dos Anjos ("Cyro dos Anjos é um dos nossos escritores mais originais, mais pessoais. Foi ele, justamente, que não imitou, não quis seguir ninguém", p. 20), é sempre a originalidade de suas realizações que será ressaltada.

\section{Algumas preferências literárias}

Já extraímos do ensaio de Guimarães Rosa elogios aos clássicos (a Bíblia, os épicos, Dante, Shakespeare, Goethe, Platão) e a dois coetâneos do autor (Clarice Lispector e Cyro dos Anjos). A enunciação de preferências literárias, porém, não se esgota nesses nomes. Sobre Dostoiévski, por exemplo, a título de curiosidade, transcrevemos este comentário interessantíssimo:

2. Se Dostoiévski tivesse conhecido os hindus - sua religião e filosofia - não teria escrito dois terços do "Os Irmãos Karamázov", d' "O Idiota", d' "O Crime e Castigo". (Bastava, igualmente, ter lido "O Mundo como Vontade e Representação": tudo o que ele pergunta, a Índia e Shopenhauer lhe respondem.) Aliás, Platão já tinha respondido, muito antes. 
3. Continuando: foi bom que assim tivesse acontecido, na minha opinião; porque aqueles três são os maiores romances existentes. [p. 1, grifo do autor]

Uma discussão sobre as afinidades entre Rosa e Dostoiévski, neste artigo, não conseguiria fugir de certa superficialidade (por exemplo, lembrar os numerosos elogios feitos a Dostoiévski na entrevista a Gunter Lorenz), até mesmo porque Rosa não explica sua avaliação. A passagem citada acima, no entanto, parece apontar para a necessidade de um estudo mais amplo sobre a relação entre os dois autores.

Os comentários sobre Augusto dos Anjos, por sua vez, são mais extensos e fecundos. A análise rosiana aborda três aspectos: o erro dos críticos que viram defeitos no poeta pelo uso de termos científicos e esdrúxulos ("Não. A este respeito, estou com o povo, que gostou do poeta justamente por seu intricado, por seu 'latim', que o punha vivo e diferente, vivo abraçado com a morte", p. 6, grifo do autor); uma espécie de análise psicológica do poeta, que justificaria seu estilo ("Porque ele sentia a morte muito perto - mais que isso, sentia demasiadamente a matéria, que [é] o verdadeiro modo de sentir a morte", p. 6); e uma avaliação crítica (“Augusto dos Anjos foi grande parce que e não malgré sua maneira abstrusa de poetar", p. 6, grifos do autor, ou "Acho que vale a pena voltar a esse autêntico poeta", p. 6, grifo do autor).

A explicitação do gosto de Guimarães Rosa por Augusto dos Anjos pode surpreender, especialmente se nunca tivermos percebido a breve referência que Rosa faz ao poeta em "Aletria e hermenêutica", de Tutameia ${ }^{23}$. Também a análise mais conceitual de Rosa, justificando a força e a qualidade da poesia de Augusto dos Anjos ("Naqueles versos altamente agônicos, em que range um cinismo feroz de tão severo, sente-se o salteio de um homem bafejado pelo frio da cova", p. 6, ou, "Ele usou a ciência como se emprega a ritualística fúnebre ou o devaneio fantasmagórico - como um retardador e um diluidor da noção vertiginosa da morte", p. 7), pode ser questionada. Importa notar, na verdade, que, em grande medida, o interesse do escritor mineiro pelo poeta paraibano está relacionado, principalmente, à questão linguística, isto é, ao uso que Augusto dos Anjos faz de vocábulos não comuns (“que fúrias e fantasmas não encontrará nessas palavras: telúrico, reintrâncias, carbono, crâneos; e que consolos misteriosos lhe sussurrarão estas outras: diatomáceas,

23 "Que o homem é a sombra de um sonho, referia Píndaro, skías ónar ánthropos; e vinda de outras eras ... - Augusto dos Anjos". ROSA, J. G. Tutaméia. Rio de Janeiro: Nova Fronteira, 1985, p. 14 . 
sáxeas, estalactites, sycómoros", p. 7, grifos do autor), e, consequentemente, à diferenciação da poesia de Augusto dos Anjos em relação à poesia de outros poetas, isto é, sua originalidade.

Um pouco mais adiante, e de forma extremamente sucinta, o elogio ao livro O louco do Cati, de Dionélio Machado, é elaborado nos mesmos termos: “(...) com muitos defeitos de forma mas autônomo, autêntico e valendo como poucos" (p. 7). Autonomia, autenticidade, originalidade eis a forma como o crítico Guimarães Rosa avalia a literatura ${ }^{24}$.

\section{Amor imortal}

José Antonio Nogueira fez parte do círculo de estudantes da Academia de Direito de São Paulo, no início do século passado, do qual participaram Monteiro Lobato, Godofredo Rangel e outros nomes menos conhecidos. Esse grupo foi denominado "Cenáculo". A descrição desse ambiente intelectual está presente nas cartas de Monteiro Lobato a Godofredo Rangel, publicadas no livro A barca de Gleyre. Faziam parte dos objetivos e práticas dos integrantes desse grupo a produção e veiculação de textos literários ou críticos em jornais. Não por acaso, portanto, como se sabe, vários de seus membros terminaram por alcançar a publicação em livro, principalmente por Monteiro Lobato ter se tornado dono de uma casa editorial. Nogueira, tendo seguido a carreira de jurista, redige, ao longo de sua vida, obras de natureza ficcional e ensaística: País de ouro e de esmeralda, Sonho de gigante e Aspectos de um ideal jurídico são alguns de seus livros. O mais destacado deles, porém, parece ter sido Amor imortal, publicado pela primeira vez na década de 1910 por uma editora do Porto, de Portugal ${ }^{25}$.

Amor imortal apresenta, na terceira edição, o subtítulo "narrativas de uma dolorosa iniciação nos mistérios da morte e do além”, tendo sido editado pela Livraria da Federação Espírita Brasileira. De fato, trata-se de obra de temática espírita, ainda que o autor, em estudo introdutório

24. Para visualizarmos a evolução do pensamento estético rosiano, faço referência novamente à carta enviada a Vicente Guimarães, em que Rosa destaca, de forma analítica, as cinco qualidades do verdadeiro artista, que coloco aqui de forma sintética: a humildade, a independência, a coragem, a sinceridade e a paciência. GUIMARÃES, V., op. cit., p. 137 .

25 Curiosamente, não consegui determinar a data exata da publicação, devido às variações nas fontes consultadas. Na apresentação da z. ed. do livro, o ano é 1915. No livro Um cenáculo na pauliceia, de Alaor Barbosa, o ano é 1912. A Biblioteca Nacional de Portugal, por sua vez, apresenta, no seu catálogo, a data de 1913. 
ao livro, declare não ser um iniciado nas doutrinas espíritas à época de sua elaboração. O livro é composto por cinco contos: "Amor imortal”, "Morrer... acabar", "Os sinos misteriosos", "Uma profissão de fé" e "Os deuses morrem”. Segundo Alaor Barbosa, o subtítulo da primeira edição era "romance filosófico" 26 , o que sugere que os contos, mesmo autônomos entre si, guardam uma inter-relação: variações sobre o tema da vida após a morte.

Em Amor imortal, Édgar e Altair casam-se e retiram-se para uma vila idílica. Sua felicidade é plena, a não ser pelo pressentimento da proximidade da morte que os assalta periodicamente. Édgar adoece e morre. Como o narrador do conto é o próprio Édgar, passamos a ter sua visão de espírito desencarnado. Em princípio, ele não se lembra de quem é, nem sabe que está morto. Finalmente, descobre Altair e sua própria condição. Altair morre de tristeza e vem se encontrar com Édgar. O casal migra para outras esferas, onde continuará vivendo seu amor. Em "Morrer... acabar", o narrador assiste aos discursos de um velho aparentemente louco, Venerando, que discorre sobre a presença da morte em todas as coisas, e sobre a inutilidade da vida (“A vida é dor, é padecimento, é agonia”, diz o ancião, p. 125). O conto termina com a morte da filha doente de Venerando. "Os sinos misteriosos" é a história de um rei, poderoso em outras épocas, obrigado a se refugiar em seu castelo, temendo os perigos de uma terra enfeitiçada. Em especial, seu terror são os dobres terríveis de sinos misteriosos, cuja fonte ninguém nunca foi capaz de encontrar. Num banquete, um ancião revela que o som dos sinos é moldado para cada pessoa. Para a filha do rei, os sinos soam maravilhosamente e ela foge do castelo para ouvi-los. O rei, na tentativa de recuperará-la, abre as portas e janelas do salão, que se afunda em trevas. "Uma profissão de fé" relata um sonho de um cavaleiro acidentado, que encontra pessoas e uma igreja num lugar desconhecido. A doutrina pregada no templo revela a harmonia existente entre corpo e espírito ("Não creiais, meus filhos e meus irmãos, que a matéria tenha realidade independente da que lhe concede o nosso espírito", p. 176), e o elogio da vida. "Os deuses morrem" é quase uma espécie de reescritura do primeiro conto. Um casal, Henrique e Tereza, muda-se para um povoado, onde vive extremamente feliz. Entretanto, a morte os ronda, sobretudo em sonhos de Henrique. Tereza morre. Após longo período de dor e luto, Henrique vê o espírito de Tereza, que se apresenta para ele, para consolá-lo e dar-lhe

26 BARBOSA, A. Um cenáculo na pauliceia: um estudo sobre Monteiro Lobato, Godofredo Rangel, José Antônio Nogueira, Ricardo Gonçalves, Raul de Freitas e Albino de Camargo. Brasília: Projecto Editorial, 2002. p. 143. 
esperanças. Henrique morre com alegria, sabendo que irá encontrar-se com a amada ${ }^{27}$.

As histórias de Amor imortal são todas instrumentos para disseminação de uma ideia: uma vida melhor existe após a morte. Por essa razão, os enredos são extremamente simples, pois José Antonio Nogueira está menos interessado em narrar grandes ações e aventuras do que em fazer reflexões sobre seu tema. Há, no entanto, grande cuidado na criação de atmosferas de suspense, que beiram o terror (algumas epígrafes de Poe sugerem onde Nogueira foi buscar seu modelo): as premonições de morte do primeiro e último conto; a loucura de Venerando acompanhada de tempestades; ou o desespero do rei, acossado pelo mistério dos sinos. A linguagem, ainda que, muitas vezes, esteja repleta de lugares-comuns, é correta, e a narração é sempre bem conduzida.

A primeira vez que o livro Amor imortal aparece relacionado a Guimarães Rosa é no estudo de Suzy Frankl Sperber, Caos e cosmos: leituras de Guimarães Rosa. Nele, a autora transcreve uma lista de "melhores livros de literatura brasileira", segundo a compôs Guimarães Rosa. O primeiro livro da lista é Amorimortal" ${ }^{28}$ Em "Liquidificador", Rosa deixa ainda mais clara essa opção:

Há um livro brasileiro que considero como eminentemente importante e se chama “Amor Imortal”, de José Antonio Nogueira. Tendo de escolher entre ele e toda a obra de Machado de Assis, para a ilha deserta, eu havia de (sem nenhum desrespeito ao mestre) preferi-lo. É um livro de forma fosca, chata e cheia de lugares comuns; mas - deixem-me ser profeta amador - um dia ele será traduzido, e verão que (sem desrespeito a ninguém) havia uma literatura brasileira. [p. 7]

A primeira maneira em de entender essa declaração de Guimarães Rosa é lembrar como ele foi sempre um grande estudioso e, muitas vezes, seguidor, de várias doutrinas religiosas e teorias esotéricas. A própria Suzy Sperber mostra isso em sua pesquisa, a partir dos livros que Rosa tinha na sua biblioteca. Alaor Barbosa, sem, evidentemente, ter tido acesso ao parágrafo anterior, oferece um esboço de explicação:

27 Descrições e análises mais detalhadas desses contos estão no livro de Alaor Barbosa, já citado.

28 SPERBER, S. F. Caos e cosmos - Leituras de Guimarães Rosa. São Paulo: Livraria Duas Cidades, 1976, p. 141. Dois outros livros/autores citados em Liquidificador fazem parte dessa lista: O louco do Cati e Eu, de Augusto dos Anjos. Também está nela Macunaíma, não referenciado no ensaio de Rosa, mas mencionado neste artigo. 
Amor imortal é uma novela platoniana. Nela, o autor expressa uma visão platoniana do mundo e da vida. Reside aí, provavelmente, a causa principal da grande consideração de Guimarães Rosa por esse livro. ${ }^{29}$

Se o próprio Rosa aponta defeitos de fatura da obra ("forma fosca, chata e cheia de lugares comuns"), e nem mesmo louva uma suposta originalidade do livro, como o fizera com outros já mencionados, resta, de fato, especular que a qualidade que faz de Amor imortal melhor do que toda a obra de Machado de Assis é a sua teoria metafísica. Guimarães Rosa acreditava que esta vida era, tal como Platão ensina, sombras de uma verdade superior (lembremos de "Sobre a escova e a dúvida": "Meu duvidar é da realidade sensível aparente - talvez só um escamoteio das percepções", p. 165), e cria na vida após a morte. Essa teoria, habilmente ficcionalizada em Amor imortal, parece bastar para consagrar o livro.

O exemplar da terceira edição de Amorimortal a que tivemos acesso faz parte da biblioteca de Guimarães Rosa conservada pelo Instituto de Estudos Brasileiros. A vantagem de compulsarmos essa cópia é poder ter contato com possíveis notas ou intervenções realizadas por Rosa no volume. Nos contos propriamente ditos, há apenas duas marcações deRosa, ambas evidenciando interesse puramente linguístico: na frase "Voltei-me de arremesso" (p. 82), a palavra arremesso está grifada; da mesma forma, a palavra aspersório recebe um grifo em outra passagem (p. 83). Um estudo que prefacia o livro, intitulado "Estudo sobre o espiritualismo moderno", também escrito por José Antonio Nogueira, recebe, todavia, um número maior de marcas de leitura. Nele, Nogueira oferece argumentos sobre a existência da vida após a morte e da possibilidade de entrarmos em contato com os mortos. Os tipos de intervenções realizadas por Rosa nesse texto são: traços verticais à margem de passagens, grifos sob trechos e o sinal de exclamação (quando, aparentemente, a concordância com o texto é acentuada); as marcações podem aparecer isoladas ou combinadas. A julgar pelo fato de Guimarães Rosa ter interagido de maneira mais explícita com o estudo introdutório do que com os contos, é possível especular que esta composição, segundo Rosa, valorizaria Amor imortal tanto ou mais que sua parte narrativa.

Guimarães Rosa anota o estudo em onze oportunidades. Para que tenhamos ciência daquilo que mais chamou a atenção do autor, ofereço uma paráfrase dos trechos destacados: o sistema solar como lugar de sofrimento e expiação; Nietzsche como um iniciado no espiritismo, que

29 BARBOSA, A. op. cit., p. 144. 
se desconhece a si mesmo (três passagens); o poder premonitório dos sonhos; a irrupção do mundo invisível; os "adormecidos", que não são capazes de ver o mundo invisível; a importância da oração; a necessidade de volta para o lugar de onde viemos; a teoria da evolução do espírito em vidas sucessivas.

Por fim, de especial interesse é a última epígrafe do estudo, de autoria de Elsa Baker ${ }^{30}$, que vem acompanhada de um sinal de exclamação adicionado por Rosa:

Quantos poemas encantadores são compostos aqui no mundo invisível e gravados em seguida nos espíritos receptores dos poetas terrestres. $^{31}$

Em “Sobre a escova e a dúvida”, a mesma ideia reaparece, agora nas palavras de Gilberto Freyre:

Haveria uma verdade aparentemente inventada - a da ficção parecendo independente da histórica, mas, de fato, verdade histórica, a qual, solta no ar - a sensibilidade ou a imaginação de algum novelista, mais concentrado na sua procura de assunto e de personagens, a apreendesse por um processo metapsíquico ainda desconhecido? [p. 178]

Guimarães Rosa, do que podemos depreender, acreditava nesses fenômenos, o que garantiu para Amor imortal posição de honra nas suas preferências literárias.

\section{Sobre a poética rosiana}

O ensaio inédito que vimos apresentando parcialmente confirma grande parte das interpretações já realizadas pela crítica sobre a literatura de Guimarães Rosa, além de dialogar com seus próprios depoimentos, cartas e publicações, como o temos indicado. Aí estão manifestados o seu gosto pelos clássicos, a sua preocupação com a correta difusão das obras

zo Elsa Baker (1869-1954), escritora americana que alegava escrever a partir da comunicação com os mortos. Seus livros mais conhecidos são Letters from a living dead man (1914), War letters from the living dead man (1915), e Last letters from the living dead man (1919).

31 Nogueira, J. A. Amor imortal. 3. ed. Rio de Janeiro: Livraria da Federação Espírita Brasileira, s.d., p. 43 . 
literárias, com ênfase no processo de tradução, o seu desconforto com a subordinação de sua obra à influência de outros autores, a valorização de uma "originalidade" da obra literária, sobretudo baseada no rompimento com o que ele considerava de pior na literatura de sua época, seu compromisso último com uma visão de mundo mais interessada em "realidades superiores" do que na vida terrena e quotidiana (fato que, muitas vezes, faz com que o acusem de alienado). Para finalizar este comentário introdutório sobre um ensaio ainda repleto de outros assuntos, resta dar relevo a duas ideias centrais para o entendimento do tipo de literatura que Rosa tinha intenção de fazer e do efeito esperado dessa literatura.

A seção VII do prefácio "Sobre a escova e a dúvida" coloca na boca do vaqueiro Zito um pressuposto estético do próprio Guimarães Rosa:

(...) um livro, a ser certo, devia de se confeiçoar da parte de Deus, depor paz para todos, virtude de enganar com o clareado a fantasia da gente, empuxar coragens. [p. 182 $]^{32}$

Em “Liquidificador”, na décima seção, Rosa narra um episódio de seu cotidiano no Itamaraty, "um dia igual aos outros”, "tudo árido e insuportável” (p.8). Chega, então, um telegrama da Embaixada de Montevidéu descrevendo o deslocamento de uma nuvem de gafanhotos pela região noroeste do Uruguai. Essa notícia, Rosa deixa entrever, dada a sua quase irrealidade, é como uma inserção da poesia na matéria bruta da vida. "Poesia, eu ia dizendo: a grandeza da vida - é isto" (p. 9), escreve Rosa, na abertura da seção.

O mesmo raciocínio se repete nas seções 37 a 39, em que o autor argumenta que "o mínimo raio de poesia incidindo num empreendimento prático, abençoa-o misteriosamente e ajuda-lhe o êxito" (p. 26). O raio de poesia em questão é a arte de nomear das coisas - a ação da língua sobre o real. O primeiro exemplo oferecido é o nome "Oscar”, usado para denominar a estatueta do prêmio da Academia de Cinema de Hollywood: segundo a lenda, reproduzida por Rosa, o nome foi sugerido pela secretária da associação, que logrou ver semelhança entre a estátua e seu tio. Maior número de exemplos éfornecido, em seguida, a partir da listagem de topônimos de várias cidades: Hamburgo, Bruges, Gand, Bruxelas:

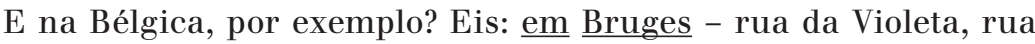
das Tesouras, rua Nova do Brejo, rua da Pimenta, rua Verde, rua

32 Não deixa de ser essa a proposta de Amor imortal: por detrás dos dramas dos personagens, há sempre a esperança a ser realizada da vida para além da morte. 
do Castanheiro, rua do Brejo, rua do Fio, rua da Cegonha, rua da Galinha, rua das Agulhas, rua do Saco Velho, rua da Mão de Ouro, rua do Poço dos Gansos, rua do Pomar, rua da Palha, rua do Galo, rua da Colina, rua das Lãs, ponte dos Burrinhos, ponte dos Leões, cais da Vaca, rua do Rabo-da-Vaca, rua dos Paneleiros, porta do Burrinho Cego. [p. 27]

É ocioso ressaltar como a questão da nomeação, tal como posta acima, é vital para a poética rosiana.

De forma ainda mais explícita e bem desenvolvida, nas seções 14 a 16 e 19, Rosa toma como ponto de partida uma frase de Edmundo da Luz Pinto ${ }^{33}$ - "um dos segredos do sucesso dos ingleses era a aplicação de métodos ordinários aos acontecimentos extraordinários” (p. 10) - e tenta justificar seu complemento: "a visão extraordinária dos acontecimentos ordinários” (p. 11, grifo do autor). Após citar Álvaro Lins, El Rey Dom Duarte e Lao-Tzé, Guimarães Rosa conclui:

A visão extraordinária dos acontecimentos ordinários é a dos gênios, dos sábios, dos descobridores. É a dos poetas. Mas devia de ser, de vez em quando, a dos políticos, dos administradores, dos homens comuns, dos pais-de-família. [p. 13, grifos do autor]

É fácil notar que essa doutrina conjuga-se com a ideia da necessidade de inserção da poesia no cotidiano, assim como reflete com precisão a forma como Rosa configura suas narrativas, especialmente em Primeiras estórias. Mais, o autor ainda acrescenta: "Como as crianças, os ingleses sabem ter uma visão extraordinária dos acontecimentos ordinários, e uma visão ordinária dos acontecimentos extraordinários" (p. 15). Não é à toa que a maioria das personagens de Primeiras estórias são crianças ou seres que, em razão de sua idade, posição social ou evolução intelectual, comportam-se como crianças ${ }^{34}$.

Em "Liquidificador", como vimos, praticamente inexistem depoimentos diretos de Guimarães Rosa sobre sua própria literatura. Ainda assim, como muitas vezes é próprio desse tipo de discurso, ao falar de outros assuntos, pessoas e eventos, o autor joga luz sobre si mesmo e sua prática literária. Walnice Nogueira Galvão havia dito que Rosa, a partir de certo momento de sua carreira, passou a se abster de explicitar

33 Edmundo da Luz Pinto (1898-1963), advogado, político e diplomata, foi membro da Academia Catarinense de Letras.

34. Isso já acontecia, devemos lembrar, nas narrativas de Corpo de baile. 
os parâmetros estéticos que deviam reger a literatura (a sua e a de seus pares). "Liquidificador", seu testamento, vem preencher, suponho, parte dessa lacuna. 